\title{
Phrenological Knowledge and the Social Structure of Early Nineteenth-Century Edinburgh
}

\section{Citation}

Shapin, Steven. 1975. Phrenological knowledge and the social structure of early nineteenthcentury Edinburgh. Annals of Science 32(3): 219-243.

\section{Published Version}

http://dx.doi.org/10.1080/00033797500200261

\section{Permanent link}

http://nrs.harvard.edu/urn-3:HUL.InstRepos:3353817

\section{Terms of Use}

This article was downloaded from Harvard University's DASH repository, and is made available under the terms and conditions applicable to Other Posted Material, as set forth at http:// nrs.harvard.edu/urn-3:HUL.InstRepos:dash.current.terms-of-use\#LAA

\section{Share Your Story}

The Harvard community has made this article openly available.

Please share how this access benefits you. Submit a story.

Accessibility 


\title{
Phrenological Knowledge and the Social Structure of Early Nineteenth-Century Edinburgh
}

\author{
Steven Shapin \\ Science Studies Unit, University of Edinburgh, 34 Buccleuch Place, \\ Edinburgh EH8 9JT, Scotland \\ Received 18 April 1975

\section{Summary} \\ This account of the conflict between phrenologists and anti-phrenologists \\ in early nineteenth-century Edinburgh is offered as a case study in the \\ sociological explanation of intellectual activity. The historiographical \\ value and propriety of a sociological approach to ideas is defended \\ against accounts which assume the autonomy of knowledge. By \\ attending to the social context of the debate and the functions of ideas \\ in that context one may construct an explanation of why the conflict \\ took the course it did.
}

\section{Contents}

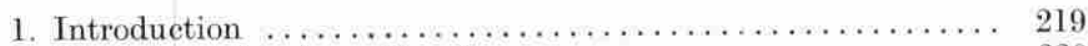

2. Historiographical considerations .................. 220

3. Perspectives on the Edinburgh social system............ 223

4. Phrenology and the social map .................. 226

5 . The social work of phrenological ideas............... 231

6. Utility and the image of science................. 234

7. Scientific methodology and social interests............. 235

8. The social meaning of ceteris paribus................ 240

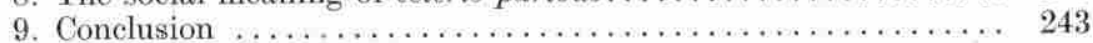

\section{Introduction}

Geoffrey Cantor's examination of 'The Edinburgh Phrenology Debate: $1803-1828$ '1 raises several questions of potentially great interest to the social historian of ideas and the sociologist of knowledge. Perhaps it is not an exaggeration to claim that Cantor's avjidance of the social dimensions of the controversy is the most intriguing of these questions. Lest this be taken as a remark showing lack of appreciation for the value of Cantor's work let me say that it is prompted by his clear demarcation of his chosen interpretive range, his superbly detailed and coherent treatment of the material which can be marshalled within that range, and his fairness in admitting to his account material which suggests the possible inadequacy of his historical focus. Indeed, with the exception of certain material additions, changes in emphasis, and disagreements over matters of factual detail, I shall have no problems in using Cantor's description of the controversy in order to advance a thoroughly social interpretation. And, although it would sharpen our methodological dispute to portray Cantor as an old school 'internalist', it is clear that such a label does not fit him comfortably. The question at issue is not whether Cantor believes

'Annals of science, 32 (1975), 195-218; eited hereafter as 'Cantor'. 
that a social interpretation of the phrenology debate is possible or not; it is why his version, which very largely shuns social factors, is incomplete.

Nowbere in his paper does Cantor proffer his account as an explanation of the Edinburgh phrenology controversy. However, I want it to be clear that $\mathrm{I}$ am in fact offering such an explanation. I do not think that one simply adds social factors to an account of intellectual factors to produce an explanation; Cantor's focus and my own differ fundamentally in their ability to generate historical explanation. Cantor's single-minded emphasis on the intellectual parameters of the controversy, and especially his treatment of intellectual methodology as autonomous, is addressed to the question of why the parties to the debate were prevented from agreeing as to the nature, facts and methods of a legitimate science of mind. They were, in his account, prevented from agreeing because they did not really ' understand ' each other, that is, because they held 'incommensurable viewpoints'. Incommensurability, once identified, can then purport to be an explanation of prolonged disagreement among knowledge communities studying the same or similar phenomena. Thus, one might assume that members of a community will 'normally' agree upon the fundamentals of their knowledge, except where incommensurability blocks effective communication, obscures signals from one section of the community to another, and, therefore, hinders the achievement of consensus. So there is a tendency in the point of view (albeit never made explicit in Cantor's paper) to regard consensus as normal and the obstacles to consensus (incommensurables) as eccentric deviations. To the extent that incommensurables are regarded as eccentricities, one may feel no need to explain their origins, their hold upon the minds of people, the 'work' they do. If we regard incommensurables as a sort of static interfering with society's clear comprehension of a given radio programme, then we may cease our historical task (as Cantor does) when we have constructed a typology of intellectual incommensurables. However, if we listen carefully to what is actually coming over the radio at the time, we may discern meaning in the 'static'. We may come to feel that incommensurables are not eccentricities, that they are normal features of discourse, that they deserve explanation in terms of the social, and that, when thus explained, we have made better sense of the phenomenon of distinguishable communities disagreeing about matters of concern to them.

\section{Historiographical considerations}

While this is obviously not the place to embark upon an elaborate discussion of the nature of explanation in history, it may help to clarify some of the procedural differences between Cantor and myself if I state here what I consider to be good guidelines for handling historical materials of the sort we are confronted with. First, I see no problem in saying that much good historical explanation consists in tracing the roots of the relatively novel and seemingly idiosyncratic to the relatively familiar and known. ${ }^{2}$ Thus, historians whose

2 The formulation is adapted from Robert K. Merton, 'Paradigm for the sociology of knowledge', in Merton, The sociology of science: theoretical and empirical investigations (ed. Norman W. Storer: Chieago, 1973), 7-40 (p. 23); and indirectly from Emile Durkheim, who regarded society and social experience as the 'familiar' in terms of which one may explain 'unfamiliar' cognitive behaviour. For example, see Durkheim, The elementary forms of the religious life (London, 1915), 439-447. For Durkheim's view of historieal methodology, see Selected writings (ed. Anthony Giddens: Cambridge, 1972), 78-82. 
work is generally accepted as 'good' and whose interpretations are widely regarded as credible frequently employ our everyday understanding of people's behaviour and motives in explaining their actions in spheres which are far removed from the everyday. Beard traces the novel altruism of the framers of the American Declaration of Independence and Constitution to their economic self-interest, as, to a certain extent, does Namier in explaining political behaviour and party-ideological allegiances in eighteenth-century Britain. ${ }^{3}$ Many historians routinely 'make sense' of ideas and intellectual behaviour by grounding the former in the social experience, interests and values of actors. Sociological sophistication is not a necessary condition for such explanation; historians do this because it integrates historical phenomena and such integration has always been regarded as one of the raisons d'être of the craft. So one need not be a Durkheimian sociologist; one need only follow one of the accepted canons of the historian's art to try to assimilate conflict in ideas to conflict among competing groups in society.

Second, historical explanation should, and very often does, aim to reduce the domain of the 'coincidental' by searching out links, parallels and connections between one existential factor and another, between existential factors and thought, between one sphere of thought and another. Historians, and not just sociologists, often function as if it is their business to search out such parallels, to cherish them, to attempt to make sense of them when revealed by making every effort to weave them into an integrated narrative. Thus, if it is revealed to us that Huttonian geologists, say, tended to be Whigs while Wernerians tended to Toryism, we do not discard this information, we do not cast it adrift in a footnote or an aside; rather, we recognise a parallel of this type as the very stuff of history, as a challenge to our capacity for integrative thought. ${ }^{4}$ In other words, as historians, we attempt to reduce coincidence in our materials. So one should look for social differences between people maintaining one intellectual viewpoint and another; having found them, we are obliged to make sense of them.

Third, historians should not start their explanatory task with blinkers on. They should not, and we can agree that many 'good' historians do not make a priori or arbitrary distinctions between one set of historical phenomena and another. Much history which we accept as 'good' wins our applause by demonstrating that the history of, for example, science cannot be explained without attention to religious thought and economic facts. ${ }^{5}$ While one may come to identify, through one's historical work, intellectual sub-cultures or other separable spheres of activity, one may also miss the mark by uncritically accepting the current location of their boundaries or by reifying academic sub-disciplines. Even when we have satisfied ourselves as to the legitimacy of

${ }^{3}$ Lewis B. Namier, The structure of politics at the accession of George III (London, 1929); Charles A. Beard, An economic interpretation of the Constitution of the United States (New York, 1913).

${ }_{4}^{4}$ See, for example, a cast-off mention of the geological theory-politics link in Leonard G. Wilson, Charles Lyell, the years to 1841: the revolution in geology (Now Haven, Conn., 1972), 73; and compare this with Martin Rudwick's serious attempt to make sense of parallels between ideas in geology and political economy in his 'Poulett Scrope on the voleanoes of Auvergne: Lyellian time and political economy', Brit. j. hist. sci., 7 (1974), 205-242.

${ }_{5}^{5}$ For example, Robert K. Merton, Science, technology and society in seventeenth century England (new ed., New York, 1970); Christopher Hill, The intellectual origins of the English revolution (London, 1965). 
the boundaries we draw between one set of historical phenomena and another, we are still well advised continually to check to see whether, by wearing disciplinary blinkers, we are not missing the chance to integrate. By the judicious removal of such blinkers Frances Yates, P. M. Rattansi, J. E. McGuire and others have taught us the price that more traditional historians of science have paid for arbitrarily distinguishing between science, metaphysics, religion and magic. Such historians ought to be praised for their integrative insight; the notion of 'externalism' does not do justice to their accomplishments. All credit to the historian who attempts to integrate social and cognitive structure; if the history of science is history, he should not be regarded as a 'polluter'.

Cantor's intellectualist account of the Edinburgh phrenology controversy is therefore only partly satisfactory. The material is there to enable integration of intellectual controversy with social conflict but he does not attempt the task. Cantor's version is incomplete, not because his aims are insufficiently sociological, but because his apparent notion of historical procedure is open to question. If my alternative account fails to convince, I hope it will be concluded that my historical ability is inadequate, not my preferred principleswhich I do not offer as either original or profound.

My purpose, in brief, is to explain the controversy by integrating the various intellectual positions taken up by the actors with their social position, interests and values. I am assuming that we intuitively know quite a lot about what happens in situations of social conflict. We know that actors or groups of actors with differing social experiences and different social interests often have difficulty in communicating with each other. We know that they often act as if they are quite unable to understand each other's meaning, even if they are using the same 'language'. It may even be that they are not really using the same 'language' and rules of language, and the historian has access to a body of sociological thought which has convineingly demonstrated that differences in language-use may arise from differences in social experiences. ${ }^{6}$ Not only the sociology of knowledge, but also much common-sense, informs us that what people believe may be conditioned at an unconscious level by how they live. And common-sense again suggests that people may consciously choose to align themselves with ideas or intellectual procedures which, they think, may serve their interests or reflect their values. ${ }^{7}$

Cantor's account is incompletely satisfying because he elects to ignore such notions of social conflict as explanatory models for the controversy in question. It is incomplete because, while he observes in passing that there were social and institutional differences between the phrenologists and their opponents, he relegates these to the category of coincidence. And, finally, it is incomplete because Cantor appears to make arbitrary distinctions between one sort of social fact and another, between one variety of cognitive behaviour and another, and between social facts and cognitive behaviour. The arbitrary distinctions do not work. Thus, instead of cogently arguing why it is proper and possible for the historian to isolate a 'scientific debate over phrenology ',

${ }^{6}$ Basil Bernstein, Class, codes and control (London, 1971).

7 Such 'common-sense' notions find articulations suggestive of their value to the historians of science in Mary Douglas's sociology of knowledge, especially her Natural symbols: explorations in cosmology (London, 1970), where both the expressive and the instrumental functions of ideas find a place. 
or why it is justifiable to separate out theological implications "from the scientific debate over phrenology ', Cantor simply does so. ${ }^{8}$ I shall begin my alternative interpretation by outlining certain social structural features of Edinburgh in the early nineteenth century, attention to which will aid in constructing a more complete account of the phrenology controversy.

\section{Perspectives on the Edinburgh social system}

The period of Edinburgh's history under consideration, roughly speaking the first three decades of the nineteenth century, is extremely interesting as regards social change and perceptions of change. Before the 1707 Treaty of Union Edinburgh had been the capital of a quasi-independent nation. The Treaty altered its status and made its political role ambiguous-something more, yet something less, than the administrative centre of a region in Great Britain. ${ }^{9}$ It was a court city which had much of the institutional equipment proper to a court city-except court and king. University, autonomous Scottish law courts, the administrative centre of the Presbyterian Kirk, libraries, and colleges of medical men all remained to remind its residents of past glories and to set Edinburgh off from other provincial towns. The lesser aristocracy and the gentry maintained winter residences in the city; they and their kin, the great lawyers, set its social tone and dominated its cultural forums. It was not an industrial city, and its leaders rather prided themselves on that fact. For industrialisation brought social disruption: "As it has no very extensive manufacturers, the city is exempt from those sudden mercantile convulsions productive of so much misery in many other of the great towns of the kingdom '.10 At the close of the eighteenth century the leaders of Edinburgh society were pleased to stress the social cohesiveness of the place, the absence of social divisiveness or the town's unique capacity for harmoniously resolving diverse social interests. ${ }^{11}$

By the early years of the nineteenth century, however, both the increasingly mercantile character of the city and its loss of cultural individuality were beginning to be widely noticed. To many minds, the rise of Edinburgh's mercantile and manufacturing elements, the decline of its political importance, the recession of its vigorous Enlightenment culture, and the break-up of the eighteenth-century social and political hegemony of the landed and professional classes seemed connected. There appeared a myth of Edinburgh-past as urban idyll. In eighteenth-century Edinburgh, prior to the French Revolution and the Napoleonic Wars,

There was no public, and very little local schism. . . The people had not yet arisen. There was no Public. The single upper class that existed

${ }^{8}$ Cantor, 203.

"For the effects of the Union on Edinburgh Enlightenment culture, see N. T. Phillipson, ' Culture and society in the 18th century provinee: the ease of Edinburgh and the Scottish Enlightenment', in Lawrence Stone (ed.), The university in society (2 vols., Princeton, New Jersey, 1974), vol. 2, 407-448.

10 Black's guide through Edinburgh (7th ed., Edinburgh, 1851), 11.

11 This frequently took the form of stressing the coneord of classes residing in the same tall buildings of the Old Town. See A. J. Youngson, The making of classical Edinburgh (Edinburgh, 1966), 235-239. In the late eighteenth-century, social solidarity in the cause of fulfilling national purposes could be advanced as an alternative to a real political life. Thus, an anonymous letter writer to an Edinburgh newspaper: 'My countrymen, it is to trade, industry, and improvement of the soil, that poor Scotland must look up for salvation, and not to the nonsense, the distraction, and the turmoil of polities' (Atticus, Caledonian mercury, 21 April 1783). 
included the nobility, the gentry, the Law, the College, the Church, and Medicine - the whole station and learning of the place and formed an aristocracy which shone undisturbed. ${ }^{12}$

Reflecting back on the 'old thing', nineteenth-century commentators would see no social friction, no threat from below, no need for special institutions of social control:

Very old men say they remember when our Old Town castes were so oiled with mutual respect that they wrought like the parts of a machine, every wheel contributing its quiet force to the general effect. There might be a little ambition now and then forcing one of a lower grade into a higher, but there was no such hatred and envy as we now see. . . Mutual respect served in place of the police-ticket. ${ }^{13}$

By the $1820 \mathrm{~s}, 30 \mathrm{~s}$ and $40 \mathrm{~s}$, 'What a change! - an avenging spirit is over usa Nemesis has shot down upon us. There is war among the castes '. ${ }^{14}$ The social classes had become conscious of their different identities and of their irreconcilable interests. Where before Edinburgh's mercantile classes were 'too subservient to be feared ', now they began to participate far more vocally in the town's cultural and political life. Yet the merchants' access to higher social status was strictly limited; ' of all places in the kingdom Edinburgh is that in which the "New Man " has the least chance of being received into the old ranks'.15 Verbal expressions of social and political discontent among the mercantile middle-classes had their counterpart in violent crime, riots and insolence among the Old Town workers. ${ }^{16}$ As the gentry, lawyers and professionals physically transported themselves across the North Loch to live in the gracious New Town, social distance separating the classes became more noticeable and, seemingly, less supportable. The mercantile middle-classes began to reject the social privileges of Edinburgh's aristocratic and professional elite, to dispute their values, manners and cultural dominance. The merchants' motto, so it was said, was 'without the cows and the bows'. By 1817 the emergent middle-classes had their own newspaper and organ for social, cultural and political comment-The Scotsman - which was critical of the Tories, the University, the Established Church, and what it saw as intellectual obscurantism. We shall see that it was no coincidence that The Scotsman supported the phrenologists in their dispute with the moral philosophers. ${ }^{17}$

While it would be possible to advance evidence to demonstrate that Edinburgh in the early nineteenth century was in fact changing in social character, and while it would be equally possible to provide indicators of an increase in social conflict, it is not part of my argument that the whole of Edinburgh's population was similarly struck by these facts. The facts impel

12 The journals of Henry Cockburn (2 vols., Edinburgh, 1874), vol. 1, 197-198.

${ }^{13} \mathrm{John}$ Heiton, The castes of Edinburgh (Edinburgh, 1859), 2. See also an English visitor's impression that late eighteenth-century Edinburgh experienced less crime than other eities: Captain Edward Topham, Letters from Edinburgh (London, 1776), 355-356.

${ }^{14}$ Heiton (footnote-13), 4-5.

15 Tbid., 192.

${ }^{16}$ See the excellent discussion of Edinburgh's civic problems in L. J. Saunders, Scottish democracy, 1815-1840: the social and intellectual background (Edinburgh, 1950), 79-96, 161-279.

17 George Combe, Answer to 'Observations on the phrenological development of Burke, Hare, and other atrocious murderers... -By Thomas Stone, Esq. (Edinburgh, 1829), 13n. For aspects of the early history of The Scotsman and its political views, see D. P. O'Brien, J. R. McCulloch: a study in classical economics (London, 1970). 
one to regard Edinburgh as a differentiated society, each distinguishable element characterised by different social experiences, values and interests; but the facts do not force one to believe that all who lived in that society saw it thus differentiated. The New Town gentry and professionals were, to some extent, physically removed from the Old Town scenes of social discontent and decay. And, since their social values were, at least in part, coloured by their orientation towards the countryside and the notion of Scottish national solidarity, such an elite might convince itself that Gemeinschaft still reigned at the same time that other residents of the city were equally convinced that Edinburgh was riven by social discord and division. If one has an interest in seeing a society as an organic, harmonious whole, the 'facts' to the contrary in no way dictate that one cannot see it that way and that one cannot elaborate a type of knowledge which reflects that perspective. Similarly, the 'facts' of social divisiveness and discord may impress themselves far more strongly on other sectors of a society, and the force with which they are felt may be stronger if one senses, as many of Edinburgh's mercantile 'new men' undoubtedly did, that the notion of social solidarity aided in the implementation of their oppression. In this case, such sectors of a society may elaborate or adhere to a type of knowledge which emphasises the real differences between men. If one lacks a theory of social differences, one cannot effectively work to overcome those differences - which is not to say that theories of social inequality are necessarily reformist or that theories of social homogeneity are necessarily conservative. It is the work these theories do in context and the associations built up around them that is important. ${ }^{18}$

Finally, if one wants to ask why some people in a given society believe one sort of thing about that society and others believe quite different things, one may point to the way in which ideas may be lodged in institutions. The moral philosophy tradition of social thought was elaborated very largely in the Scottish universities and, especially, in the University of Edinburgh. It might be possible to show that the university professoriate was recruited from a specifiable, non-random sector of Scottish society; and it might also be possible to show that the student body, socialised into the moral philosophy tradition, was hardly a cross-section of Scottish youth. ${ }^{19}$ In any case, an institution like a university or a medical school is a distinct part of society. If the

18 See similar orientations in Barry Barnes, Scientific knowledge and sociological theory (London, 1974), especially chapter 6; Charles E. Rosenberg, 'Science and American social thought ', in D. D. Van Tassel and M. G. Hall (eds.), Science and society in the U.S. (Homewood, Illinois, 1966). 135-162, esp. p. 143; and Rosenberg, "The bitter fruit: heredity, disease, and social thought in nineteenth-century America', Perspectives in American history, 8 (1974), 189-235 (esp. pp. $214-217)$.

${ }^{19}$ For a study suggestive of Edinburgh parallels, see W. M. Mathew, "The origins and occupations of Glasgow students, $1740-1839^{\circ}$, Past and present, 33 (1966), 74-94. During the early nineteenth century complaints by merchants and skilled artisans that the University of Edimburgh was socially exclusive were legion; for example: 'It is obvious, that the means of scientific instruetion in this metropolis are wholly inaccessible to the mass of the middling elasses. The high fees payable to the professors in the University, ... and the inconvenient hours at which the lectures are delivered, render attendance there impracticable, except to the few who are destined for the learned professions, or whose eircumstances render them independent of the drudgeries of professional or mercantile pursuits' (Popular education. Address to the public; by the Directors of the Edinburgh Philosophical Association (Edinburgh, 1835?), 6). Of course, these complaints did not prevent the Edinburgh elite from portraying their university as open to all the talents, for example, [J. G. Lockhart], Peter's letters to his kinsfolk (2nd ed., Edinburgh, 1819), vol. 1, 197. 
' facts' of the wider society change, there is no necessity that the institution's ideas will change in recognition of them. An institution's ideas and values may be regarded as the ideas and values of those people who participate in it, or they may be regarded as the ideas and values of the society before it underwent certain kinds of changes. Institutions can ossify ideas. This is interesting in the present connection because the war between the phrenologists and the moral philosophers may, in large measure, be treated as a conflict between university professors and those exposed to university teaching, on the one hand, and those not associated with the university, on the other. ${ }^{20}$

\section{Phrenology and the social map}

All this is by way of preface to socially locating adherence to phrenology and moral philosophy in different sectors of early nineteenth-century Edinburgh society. There are two levels on which one should socially identify the Edinburgh phrenologists - the level of those who propagated and elaborated phrenological ideas and the level of those who more or less passively found those ideas congenial, that is, the audience for phrenology. No special defence is needed for treating the role of the audience on a par with that of the major actors. In phrenology we are dealing with a body of thought which was shared by many in society and we would miss many nuances of its development and significance if we omitted to examine it as collective representation. ${ }^{21}$ Both actors and audience for phrenology were significantly different from actors and audience for moral philosophy.

Cantor himself points to the ' considerable support ' Edinburgh phrenology received 'from the lower-middle and working classes',22 $\mathrm{He}$ correctly mentions hostility towards phrenology on the part of Leonard Horner's School of Arts and other educational institutions, but is mistaken in arguing that such antipathy diminished phrenology's popular appeal in the city. Emotional resistance to the new system from the School of Arts, but especially from the university professoriate and medical profession, should be read as a sign that phrenology had real social support and that its aims conflicted with the values of established institutions. The 'popular appeal [of phrenology]' was not, as Cantor claims, 'less noticeable in Edinburgh than in some other cities '. ${ }^{23}$ Propagandists for phrenology, while recognising the strength of their local opposition, were quite clear that

More has been effected, on behalf of the science, in this one city, than in all the rest of Britain taken together. . . . It will be the high and legitimate boast of [the early phrenologists'] descendants ... that Phrenology first took

\footnotetext{
${ }^{20}$ Combe's attempt to obtain an Edinburgh University chair was half-hearted at most. Later I shall show that no members of the Edinburgh professoriate were members of the Iocal Phrenological Society during the height of the controversy. By the late nineteenth century, advocates of phrenology could even claim that their system was essentially a radical, "people's" scienee, which would lose its vigour if ever it became a respectable university study; for example, W. Mattieu Williams, A vindication of phrenology (London, 1894), 308. More generally, I find it appropriate and valuable to identify the Edinburgh phrenological community as social and cultural 'outsiders' and their major opponents as 'insiders '; my distinction owing something to Robert K. Merton, ' The perspectives of insiders and outsiders ', in Merton (footnote 2), 99-136.

${ }^{21}$ One attempt to examine the audience for science as an active factor is Steven Shapin, 'The audience for science in eighteenth century Edinburgh', History of science, 12 (1974), 95-121. 22 Cantor, 201.

${ }^{23}$ Ibid.
} 
root, first flourished, and first bore its inestimable fruits in the eity of Edinburgh. ${ }^{24}$

Edinburgh was a battleground for the new system and its critics; the size and esprit de corps of both camps was considerable. But one does not mass an army without an enemy, and the venom of the anti-phrenologists towards a body of ideas which they often characterised as being beneath their attention points to phrenology as a serious threat.

The exclusion of phrenology from the curriculum of the Edinburgh School of Arts was a decision endorsed by its Board of Directors, a body which, at the time, was composed of at least three University of Edinburgh professors, the Lord Provost of the city and a number of respectable lawyers and ministers. The School never pretended to a democratic form of control in which its working and lower middle-class students had any power; the Directors decided upon the curriculum at all times. ${ }^{25}$ By way of contrast, in local educational organisations where the skilled working-classes and the lower middle-class were catered for and where students had a measure of curricular self-determination, phrenology always had an honoured position. The merchant-controlled Edinburgh Philosophical Association, founded in 1832, offered George Combe's phrenological lectures and found them to be the best attended of any of their courses. $^{26}$ From 1836, one Sydney Smith, the surgeon W. B. Hodgson, and later, the advocate James Simpson provided phrenological lectures at 1 penny to Edinburgh's working-classes under the auspices of the Society for the Diffusion of Moral and Economical Knowledge. The audience for these lectures often numbered over 500 and there were occasions on which hundreds more workers were turned away when the Cowgate Chapel was filled to capacity. ${ }^{27}$ And, of course, there was the largely middle-class audience attracted to Combe's own lecture series which he offered from 1822; at two guineas per session he had an audience varying from thirty to seventy. But these figures are nothing compared to the thousands of Edinburgh workers and merchants who attended cheap or free phrenological lectures during the $1830 \mathrm{~s}$. Nor is this picture of phrenology's immense appeal to the working and lower middleclasses peculiar to Edinburgh; many, perhaps most, Mechanics' Institutes throughout England and Scotland offered courses on the new system. By the mid-1830s there were at least thirty phrenological societies in existence, attracting audiences of provincial merchants and professional men. ${ }^{28}$

Both phrenologists and their Edinburgh opponents recognised the social differences between the two camps and considered them to be important.

${ }^{24}$ Hewett C. Watson, Statistics of phrenology (London, 1836), 132-133. Also see George Combe, 'Letter on the prejudices of the great in science and philosophy against phrenology ', Phrenological journal, 6 (1829-30), 14-38 (p. 28), where Combe quotes the Edinburgh weekly gournal as saying "We believe that Phrenology is nowhere on so respectable a footing as in our own city '.

${ }^{25}$ First report of the Department of Science and Art (Sessional papers . . . of the House of Lords . . . 1854, vol. 45) (London, 1845), 385-397; and J. W. Hudson, History of adult education (London, 185I), 39-42. On Combe and the School of Arts, see Charles Gibbon, The life of George Combe (2 vols., London, 1878), vol. 1, 254.

${ }_{26}$ On the Philosophical Association and its origins in Combe's public phrenological lectures, see James Simpson, The phitosophy of education (2nd ed., Edinburgh, 1836), 238-249, and Popular education (footnote 19).

27 The Scotsman, 9 April 1836; Simpson (footnote 26), 256-263; Phrenological journal 10 (1836$37), 630-631$.

28 Figures in Watson (footnote 24), 109-168, 218-234. 
In 1834 George Combe wrote that 'phrenology advances here rapidly in the humbler grades of the middle rank. The philosophers of the old school and the religious combine to denounce it in the higher, and it scarcely gains ground amongst them, except with the young '. ${ }^{29}$ In the same year an anonymous anti-phrenologist (probably William Pyper, teacher of Latin in the Edinburgh High School) attacked Combe's Philosophical Association lectures, not so much on the basis of faults in phrenological doctrine as on the basis of the pernicious effects to be expected from exposing particular social groups to such ideas:

When considered as addressed to a promiscuous audience, and chiefly intended for the benefit of young persons in the middle and lower classes of life, these [phrenological] lectures cannot be too strongly reprobated. ... Their direct tendency appears ... to be-to render the great mass of the community discontented with their condition, and with the existing relations of society ... Phrenology ... now appears as the disturber of the peace and well-being of society. ${ }^{30}$

This particular anti-phrenologist was responding to two features of Edinburgh phrenology -its pronounced association with the working and middle-classes and its connections with movements for social reform. Later on, I shall very briefly outline some of the phrenologists' reformist activities and ideas. However, at this point, I want to establish that the phrenological elite, as well as the audience for Edinburgh phrenology, may also be socially located and distinguished from other Edinburgh literati and philosophers.

One can readily locate the apex of the Edinburgh phrenological community in the Phrenological Society which was founded in 1820. Among formally constituted cultural institutions of early nineteenth-century Edinburgh the Phrenological Society may be characterised as an 'outsider' group. Its membership was less genteel, less aristocratic, less politically and socially powerful than that of any other chartered scientific, philosophical or literary society of contemporary Edinburgh. This is not to say that no aristocrats belonged to it or that it may be labelled a 'lower middle-class' group; with an entry fee of one guinea it could hardly have expected to recruit the impecunious. The Phrenological Society is an 'outsider' group when compared with the other members of the set of institutions constituting the contemporary cultural elite, for example, the Society of Scottish Antiquaries, the Society of Scottish Arts, the Wernerian Natural History Society, the Caledonian Horticultural Society, and, especially, the Royal Society of Edinburgh. The Royal Society represented the institutional pinnacle of the local cultural hierarchy. Literati and men of seience prized acceptance by the Royal Society far more highly than they did membership in any other Edinburgh society. Fellows rarely omitted to append 'F.R.S.E.' after their name on publications, and almost as rarely remembered to add lesser societies' initials. ${ }^{31}$ It is therefore interesting to point out certain differences between the membership of the Phrenological Society and that of the Royal Society

${ }^{29}$ Gibbon (footnote 25), vol. 1, 300.

${ }^{30}$ Edinburgh Advertiser, 24 December 1833. The Advertiser was a high-Tory organ.

${ }^{31}$ On the elite social and cultural status of the Royal Soeiety of Edinburgh, see Steven Shapin, 'Property, patronage and the polities of science: the founding of the Royal Society of Edinburgh', Brit. j. hist. sci., 7 (1974), 1-41 (esp. pp. 36-40); and his 'The Royal Society of Edinburgh: a study of the social eontext of Hanoverian seience' (unpublished Ph.D. thesis, University of Pennsylvania, 1971), chs, 6-8. 
of Edinburgh in order to further characterise the social and eultural standing of the local phrenological community.

Table 1 reveals several striking differences between the phrenological elite and the Royal Society. No Edinburgh University professors belonged to the former in $1826,{ }^{32}$ whereas all Edinburgh professors were Fellows of the Royal Society. Second, one finds that the proportion of gentry and aristocrats was more than three times as high in the Royal Society as it was in the Phrenological Society. And third, one sees an even more marked difference between the two groups in the proportion of merchants, artisans and the like. Such social distinctions lend support to the view that even the elite of the Edinburgh

\begin{tabular}{|c|c|c|c|c|}
\hline \multirow{2}{*}{ Occupation $^{a}$} & \multicolumn{2}{|c|}{$\begin{array}{c}\text { Phrenological } \\
\text { Society }(1826)^{b}\end{array}$} & \multicolumn{2}{|c|}{$\begin{array}{l}\text { Royal Society of } \\
\text { Edinburgh (1820) }\end{array}$} \\
\hline & $\begin{array}{l}\text { Number } \\
\text { of } \\
\text { members }\end{array}$ & $\begin{array}{l}\text { Per- } \\
\text { centage }\end{array}$ & $\begin{array}{c}\text { Number } \\
\text { of } \\
\text { members }\end{array}$ & $\begin{array}{c}\text { Per- } \\
\text { centage }\end{array}$ \\
\hline University of Edinburgh professors & 0 & 0 & $26^{d}$ & 11 \\
\hline Professors at other institutions & 0 & 0 & 18 & 7 \\
\hline Gentry and aristocrats & $4^{e}$ & 5 & $39^{f}$ & 16 \\
\hline Merchants, artisans, artists and engineers & 20 & 23 & 16 & 6 \\
\hline Law & 27 & 31 & $40^{g}$ & 17 \\
\hline Medicine & 17 & 20 & 54 & 22 \\
\hline Ministers & 6 & 7 & 17 & 7 \\
\hline Military & 3 & 4 & 12 & 5 \\
\hline Other/unknown & 9 & 10 & 22 & 9 \\
\hline Total & 86 & 100 & $244^{h}$ & 100 \\
\hline
\end{tabular}

Table 1.

Occupations of members of the Phrenological Society and Fellows of the Royal Society of Edinburgh.

\footnotetext{
a Occupation of members in 1826 for Phrenological Society; in 1820 for Royal Society of Edinburgh.

$b$ Source of information: Phrenological journal, 3 (1825-26), 478-481, and Minute book of the Phrenological Society, vol. 1 (Edinburgh University MS. Gen. 608). Figures refer to 'Ordinary' members only.

c Source of information: Steven Shapin, ' Collective biography of Fellows of the Royal Society of Edinburgh, 1783-1820' (Typescript appendix to my Ph.D. thesis, deposited in the Royal Society of Edinburgh); see Shapin references in footnote 31. Figures refer to 'Ordinary' Fellows only.

$d$ This figure represents the entire Edinburgh professoriate in 1820. Clerical and medical professors are included in this category and not in 'Law' and 'Medicine'.

e Sir George Stewart Mackenzie, W. C. Trevelyan. D. Gordon Hallyburton, William R. Henderson.

$f$ Many landed lawyers are included in the eategory of 'Law'.

$g$ The majority of Seottish Senators of the College of Justice belonged to the Royal Society, whereas no lawyer-Phrenologists had achieved that status.

$h$ This figure is about 40 larger than the total Fellowship of the Royal Society given in its Transactions, 9 (1823), 517-524. The larger figure includes all Fellows elected from 1783 to 1820 , alive in 1820, and not known to have resigned Fellowship. There is no reason to suspect that the diserepancy would affect the percentages.
}

${ }^{32}$ Although two members later became Edinburgh professors: The Rev. David Welsh in 1831, and John Shank More in 1843. 
phrenologists constituted an 'outsider' group, and give some credence to contemporary assertions that local phrenology ' could number among its open advocates... only a few lounging lawyers and obscure physicians ', who were achieving much even to attract the notice 'of men whom the voice of the country had invested with something like a reasonable capacity to decide upon its merits'. 'Hitherto', the critic continued, 'no individual of acknowledged eminence, no society of honourable standing or credit, had held it worthy of reply.... ${ }^{33}$ Another indicator of the local phrenological community's 'outsider' status is provided by Table 2. Here we see that only $7 \%$ of the members of the Phrenological Society in 1826 were then Fellows of the Royal Society of Edinburgh. The proportion of F.R.S.E.s in the three other contemporary societies chosen ranges from nearly twice as high to over five times as high as in the Phrenological Society.

From 1825 to 1827 Sir William Hamilton, then Edinburgh Professor of Civil History, delivered a series of anti-phrenological essays to the Royal Society of Edinburgh. By the rules of that Society no reply to Hamilton's arguments was permitted and it was not until early in 1830 that the Royal Society was addressed on the subject of phrenology by a proponent of that system. Sir George Stewart Mackenzie, one of the few members of the Phrenological Society who was also a Fellow of the Royal Society of Edinburgh, outlined the system to 'that learned body', claiming that 'there is nothing in social life which [phrenology] does not embrace; and its genuine application

\begin{tabular}{|l|c|c|c|c|}
\hline \multicolumn{1}{|c|}{ Society } & Year & $\begin{array}{c}\text { Number } \\
\text { of } \\
\text { members }\end{array}$ & $\begin{array}{c}\text { Number } \\
\text { of } \\
\text { F.R.S.E.s } \\
\text { in Society }\end{array}$ & $\begin{array}{c}\text { Percent- } \\
\text { age of } \\
\text { F.R.S.E.s } \\
\text { in Society }\end{array}$ \\
\hline Phrenological Society & 1826 & 86 & $6^{a}$ & 7 \\
\hline Caledonian Horticultural Society $^{b}$ & 1815 & 227 & 29 & 13 \\
\hline Wernerian Natural History Society $^{c}$ & 1820 & 100 & 39 & 39 \\
\hline Society of Scottish Antiquaries $^{d}$ & $1780-$ & 310 & $77^{f}$ & 25 \\
\hline
\end{tabular}

Table 2.

Overlap between the Royal Society of Edinburgh and other societies.

${ }^{a}$ Sir George Stewart Mackenzie (F.R.S.F. in 1799), Patrick Neill (1814), John Shank More (1820), Robert Hamilton (1821), W. C. Trevelyan (1822) and William Bonar (1823).

b' Ordinary' members only. Source: Memoirs of the Caledonian Horticultural Society, vols. $1-4$.

c'Resident' members only. Source: Memoirs of the Wernerian Society, vols. 1-4.

$d$ 'Ordinary' members only. Source: Archaeologia scotica, vol. 3.

$e$ The figures refer to all ordinary Fellows elected during the entire period.

$f$ This is the number of Antiquaries who were F.R.S.E. on election or who became F.R.S.E. up to 1820 .

3s Anon., Sir William Hamilton and phrenology. An exposition of phrenology; shewing the complete inefficacy of the objections lately advanced in the Royal Society, and the real grounds on which the system ought to be assailed (Edinburgh, 1826), 4-5. 
is to the improvement of mankind ' ${ }^{34}$ Mackenzie's exposition fell on deaf ears, for, as he said to the Society: 'I believe, with one or two exceptions, [I am] the only member who has avowed conviction of its truth'.35. Just as phrenology made no headway in the elite Royal Society, neither did it find any favour among the University professoriate. In 1827 Hamilton again delivered an anti-phrenological lecture to a popular audience in a University elassroom. George Combe was denied permission to reply at the end of the lecture and was then refused permission to use a University room to deliver a formal response to Hamilton. In spite of Combe's personal friendship with Principal Baird, and in spite of Combe pointing out that the University of Cambridge had offered similar facilities to Spurzheim, the Senatus Academicus unanimously rejected his request. ${ }^{36}$

\section{The social work of phrenological ideas}

My intent has been to make several points about the social location of phrenological and anti-phrenological belief's very clear before proceeding to relate this social positioning to the nature and progress of the controversy. First, it should be clear that the phrenological system found a large and receptive audience among Edinburgh's working and lower middle-classes; second, that the proponents and elaborators of phrenology were themselves an outsider group vis-à-vis the city's elite literati; third, that, with very few exceptions, Edinburgh's established cultural institutions resisted the new doctrine and did so with considerable vehemence.

Unlike Cantor I see the connections between phrenology and social reform as important from the outset of the debate, and I want to devote some attention to the nature and timing of these connections. Recent work has shown beyond any question that British phrenology was a social reformist movement of the greatest significance. ${ }^{37}$ Combe and his circle vigorously, and to some extent

34 'Essay read by Sir Geo. S. Mackenzie, Bart., to the Royal Society of Edinburgh, January $1830^{\prime}$, Phrenological journal, 6 (1829-30), 332-343, 355-365 (p. 334). A manuscript note by John Robison, then General Secretary to the Society, records that Mackenzie commenced his presentation on 8 December 1829 and concluded it on 1 February 1830. (The note is kept in the Archives of the Royal Society of Edinburgh.) The minute-books of the Royal Society record anti-phrenological papers delivered by Sir William Hamilton on 19 December 1825 , 6 February 1826, 2 April 1827 and 18 February 1829. On 5 March 1832 the volumes of the Phrenological journal presented to the Royal Society by Mackenzie ' were direeted to be returned to him' (Minutes of Council, p. 73). A pro-phrenological poetical satire attacked Hamilton and the Royal Society in the following terms:

Oh! 'twas a noble feat thy strength to try

'Gainst rival tongues - forbidden to reply;

And girdled round by men of 'stablished learning,

Pour forth thy words when sure of none returning.

Anon., Phrenology in Edinburgh (Edinburgh, 1830), 16.

${ }^{35}$ 'Essay read by Mackenzie ' (footnote 34$), 332$. He was certainly exaggerating his isolation somewhat; see table 2 , footnote $a$.

36 'Controversy with Sir William Hamilton', Phrenological journal, 4 (1826-27), 377-407 (pp. 378-380). The University Senatus minute concerning this decision is to be found in Minutes of the Senatus Academicus for 16 April 1827.

${ }^{37}$ For example, David A. De Giustino, 'Phrenology in Britain, 1815-1855: A study of George Combe and his circle ' (unpublished Ph.D. thesis, University of Wisconsin, 1969), esp. chapters 6-7; his The conquest of mind: phrenology and Victorian social thought, (London, 1975); Angus McLaren, 'Phrenology: medium and message', Journal of modern history, 46 (1974), 86-97; Terry Parssinen, 'Popular science and society: the phrenology movement in early Victorian Britain', Journal of social history, (Fall, 1974), 1-20; and the fortheoming doctoral dissertation by Roger Cooter of Cambridge University. 
successfully, agitated for penal reform, more enlightened treatment of the insane, the provision of scientific education for the working classes, the education of women, the modification of capital punishment laws and the re-thinking of British colonial policy. Phrenology-based reformism in Britain was founded upon a social optimism which maintained that the manipulation of environmental factors could improve the human condition. The various faculties of mind, according to the phrenologists, are given - they are innate. However, George Combe and the great majority of British and American phrenologists believed that environmental influences could be brought to bear to stir one faculty into greater activity, or to offset the undesirable hyperdevelopment of another. Not just the size of the organ of, say, amativeness, but also its tone was held to be responsible for the degree to which its possessor manifested amative behaviour. ${ }^{38}$ Thus, self-awareness and then training of the faculties might result in shifting human behaviour from what it would be if the innate faculties worked undisturbed. This environmentalism of the British phrenologists is what lent itself to legitimating a programme of social reform. Thus George Combe in 1834:

My sentiments are Whig, and I am very much in favour of the present ministry. .... My view of human nature is that men require, 1st, knowledge, and 2nd, training of their moral and intellectual faculties, before they can be trusted with power or be made the arbiters of their own destinies with advantage to themselves; but I believe that men collectively, when enlightened and trained, will go right and promote their own happiness; and hence that all churches and oligarchies that pretend to reign over either the minds or properties of mankind permanently ought to be overthrown, but not till the people are rendered rational by the means foresaid. ${ }^{39}$

Now it should be made clear that there is nothing about phrenological doctrine, as handed down from Gall, that logically dictates its deployment as the legitimator of social change. In fact, Continental phrenology had rather conservative associations. ${ }^{40}$ After all, Gall identified as his enemy Enlightenment thinkers, in particular Helvetius, who maintained that education could be all powerful in shaping man's character. The three fundamental doctrines of phrenology, it might be argued, readily lend themselves to a social programme which would be opposed to or pessimistic about the possibility of ameliorative change: (1) that the brain is the organ of mind; (2) that the brain is an aggregate of several parts, each subserving a distinct mental faculty; (3) that the size of the cerebral organs is an accurate index of power or energy of their function. ${ }^{41}$ If, as the phrenologists believed, the size of the cerebral organs was laid down at birth, that is, that they were innate, then there is no logical reason why the system should not have been employed to justify the social status quo, the impossibility of rehabilitating criminals, curing the insane, and so on. But in fact phrenology was used in Britain

\footnotetext{
3s The analogy between size and exercise in the muscles and size and exercise of the cerebral organs is made in Andrew Combe, 'On the influence of organic size on energy of function', Phrenological journal, 4 (1826-27), 161-188, and in many standard phrenological texts.

ss Gibbon (footnote 25), vol. 1, 302; italies in the text.

40 Owsei Temkin, 'Gall and the phrenological movement ', Bull, hist. med., 21 (1947), 275-321.

41 These three elements of phrenology dogma may be found, with minor variations, in practically any Edinburgh work; see, for example (footnote 36), 394. I have omitted the usual ceteris paribus qualification from doctrine (3), as I shall be treating it separately below.
} 
and America for quite different purposes. One cannot understand how ideas are used and what significance they have by logically inspecting their content; one can only understand their significance by attending to their deployment in specified contexts.

It is, in the end, misleading to say that up to 1828 , presumably chosen as the date of publication of Combe's Constitution of man, "the debate in Edinburgh was centred on scientific issues' and that 'thereafter the phrenologists progressively became more involved in examining the subject's social implications'. ${ }^{2}$ 'Social implications' were the debate, as much as technical issues were. Besides, Cantor's tendeney to separate out the scientific from the social lends itself to an incomplete interpretation of the evidence. In 1820, the year in which the Phrenological Society was established, one of the very first books published in Edinburgh advocating the system made it clear that 'social implications' were part and parcel of the programme: "The legitimate objectives of Phrenological Science, after it has unfolded the true philosophy of the human mind, are improvements in criminal legislation, in education, and the treatment of insanity '.43 George Combe's 1819 Essays on phrenology contains 35 pages on the utility of phrenology in education and explicit statements of the social relevance of the study:

The utility of [phrenology], therefore consists in this, that it gives us a clear and philosophical view of the innate capacities of human nature, and of the effects of external circumstances in modifying them ... The subjects on which it is peculiarly fitted to throw a powerful light are Education, Genius, the Philosophy of Criticism, Criminal Legislation, and Insanity. ${ }^{44}$

Revealing of the readiness of phrenologists to further enunciate the study's social implications is Combe's statement that 'should the public take an interest in the science, additional illustrations of its application may be given at a future period '. ${ }^{45}$ Another member of the early Phrenological Society said in 1822 :

What I would desire is, that these studies should be directed to improving our knowledge in the philosophy of the human mind, and to giving such an insight into the nature and constitution of man, as should enable us to improve our systems of education and government. ${ }^{46}$

And, of course, Spurzheim (more influential by far than Gall among Combe's circle) in 1821 published his View of the elementary principles of education.

By 1823 George Combe was applying 'the principles of phrenology to all the incidents of life'. The first numbers of the Phrenological journal (1823-24) and the Transactions of the Phrenological Society of Edinburgh (1824) are full

42 Cantor, p. 202.

${ }^{43}$ Sir G. S. Mackenzie, Illustrations of phrenology (Edinburgh, 1820), 28.

44 [George Combe], Essays on phrenology (Edinburgh, 1819), 304-306.

45 Ibid., 306; my italies.

${ }^{46}$ [William Scott], Observations on phrenology (Edinburgh, 1822), 51; my italies. Perhaps the fullest force of phrenology's social implications is felt in these comments by Hewett Watson in 1836: "Individuals may be disposed to smile if we say that political power must fall into the hands of the phrenologists, in the course of a few years. But let them smile, as the Tories smiled at the Reformers, it will not change the course of events. If our statesmen do not become phrenologists, the phrenologists will become the statesmen' (Watson (footnote 24), 224).

A.S. 
of 'social implications' of a reformist nature. ${ }^{47}$ Cantor would have been right had he confined himself to saying that there was a period in the $1820 \mathrm{~s}$ when the phrenologists made strenuous efforts to persuade the moral philosophers and anatomists that phrenology was conceptually and technically reputable; and he would also have been right to identify a period during which Edinburgh phrenology very largely consisted in expositions of Spurzheim and Gall rather than in its own indigenous formulations. Yet to say that there was a technical debate is not to say that it can be or was separated from social conflict, nor that such a technical debate does not reflect social and institutional divisions.

\section{Utility and the image of science}

Having made the points that Edinburgh phrenology was socially located among outsider groups, that such groups in the early nineteenth century were in conflict with a dominant elite, and that the social programme of the phrenologists was well known to its adherents and enemies, I shall proceed to show how such considerations may explain certain dimensions of incommensurability in the controversy. For reasons of space I shall confine myself to discussing just two fundamental aspects of the controversy-methodological disagreements and the significance of the ceteris paribus qualification of the phrenologists' doctrine, that is, that all things being equal the size of the cerebral organ is a measure of its power of function.

One of the most powerful arguments advanced by the Edinburgh phrenologists against their enemies was that the new system had the characteristics of science whereas moral philosophy did not, and was, in fact, anti-scientific. The image of 'being scientific' which the phrenologists drew upon and which had wide appeal to their audience consisted largely in utility and empiricism. Nothing could be regarded as a true science which did not prove itself by the usefulness of its fruits; neither could any study be so regarded if it did not centrally rely upon observation and induction from the observable. Moral philosophy, the phrenologists argued, failed on both counts. In 1821 they claimed that a "great defect of the philosophy of the mind is its inutility'; moral philosophy 'affords no other advantage than a field for intellectual skirmishing ... Such a series of inconsequences in philosophy has never been exhibited in any other branch of science since the days of the Alchemists '.48 Moral philosophy, in the persons of Dugald Stewart and Thomas Reid, having claimed its potential social utility, ${ }^{49}$ the observer was now entitled to judge its fruits. Quoting Stewart's assertion of the 'practical

47 The Minute book of the Phrenological Society (Edinburgh University MS. Gen. 608) records the following papers, some of which were subsequently printed: George Combe, 'A phrenological analysis of Mr. Owen's new views of society' (January 1824); George Lyon, 'Phrenological causes of the different degrees of liberty enjoyed by different nations ' (five papers read from January 1825 to February 1827); The Rev. James Whitson, 'Phrenological observations on edueation ' (February and April 1825); and George Combe, 'Origin and progress of society ' (March 1825).

48 'Review of Illustrations of phrenology . . . by Sir G. S. Mackenzie, Bart. ', Edinburgh monthly review, 5 (1821), 90-108 (pp. 91, 94).

49 George E. Davie, The social significance of the Scottish philosophy of common sense: the Dow Lecture delivered at the University of Dundee, 30 November 1972 (Edinburgh, 1972). 
utility' of common-sense philosophy, George Combe compared its performance with that of recognised sciences:

Well might Mr. Stewart anticipate its 'practical utility'; for, if metaphysical science can yield fruit in any department, it may be expected to do so in this [that is, identifying varieties of intellectual character among men]. . . . Chemistry, for example, would be little esteemed for its practical utility, if it enabled its professors only to deliver elegant and ingenious discourses concerning the elementary prineiples of matter, but not to combine them so as to produce beneficial results .... And yet this is the condition of metaphysical philosophy at the present moment. ... It is obvious that, if the science of Mind were in the same state of forwardness as Chemistry or Natural Philosophy, society would now be reaping these fruits of its cultivation..${ }^{50}$

Attempting to link current concern about social conflict to a judgement on the inutility of moral philosophy, Mackenzie suggested in 1830 that

the increase of crime, and the inefficacy of thousands of benevolent projects for ameliorating the condition of society, are owing to the state of mental philosophy ... Until mental philosophy improves, society will not improve. However interesting it may be to superior minds seeking their own gratification, to trace the progress of metaphysical inquiry, they have not found that metaphysicians have produced any thing attractive on account of its practical utility, however ingenious, eloquent, and profound their speculations may have been. ${ }^{51}$

However, phrenology, as Mackenzie told the affronted Royal Society of Edinburgh, 'has solved the problem on which the whole practical utility of mental philosophy depends...

In advocating utility as a test of credibility, the phrenologists were making an argument which answered to the utilitarian values of the mercantile classes and which, at the same time, condemned academic values of 'knowledge for the sake of knowledge'. 'We have often said', a proponent announced in 1829 , 'that Phrenology is either the most practically useful of sciences, or it is not true '. ${ }^{52}$ In time, they argued, the utility of the system will convert even its most bitter opponents; acceptance of the validity of the idea should follow (and would follow) demonstration of its practical results. ${ }^{53}$ It should be pointed out here that when people have a belief in establishing truth through use, they decide the useful purposes to which they wish to direct their ideas according to their social and political interests. Thus, in asking others to accept useful applications as a sign of validity they are making the impossible request that another group share their social and political interests. In this way, the phrenologists' social reformism and their utilitarian test for truth entered into the making of incommensurability.

\section{Scientific methodology and social interests}

However, I want to move from the phrenologists' image of science as useful knowledge to their related view of scientific methodology. And again, I shall show how their methodological disagreements with the moral

\footnotetext{
${ }^{30}$ George Combe, 'On the progress and application of phrenology', Transactions of the Phrenological Society, 1 (1824), 1-62 (pp. 48-50).

${ }_{51}$ Mackenzie (footnote 34), 356-357.

52 'Practical phrenology', Phrenological journal, 5 (1828-29), 426.

53 ' On the progressive diffusion of phrenology', Phrenological journal, 10 (1836-37), 346-352 (p. 349).
} 
philosophers may be socially explained. I shall suggest that the phrenologists' emphasis upon empirical methods in mental science reflects their socially-based anti-elitism and their commitment to broadening the social base of participation in culture. In making this point it may be useful to bear in mind the many parallels between the methodological dispute in question and that between the Baconians and the Scholastic philosophers of seventeenth-century England. In both eases one of the purposes served by the deployment of empiricist methodologies was to justify the participation in scientific culture of social groups previously excluded. In both cases methodological conflict reflected social and institutional conflict, and in both cases useful application, as defined by the emergent group, was advanced as a test of valid knowledge. Social historians of science might do well to see to what extent other outcroppings of empiricism and inductivism may be illuminated by giving attention to the social boundaries of cultural participation.

By 1818, as Gibbon relates, George Combe was able to offer one fundamental methodological dictum to all who applied to him for advice in their studies: "Observe nature for yourselves, and prove by your own repeated observations the truth or falsehood of phrenology $",{ }^{54}$ In his first publication on phrenology, in 1817, Combe made clear that one of the great attractions of the new system, as contrasted with moral philosophy, was its foundation on 'actual observations'. ${ }^{55}$ Let the people, he said then, 'trust to their own observations '; let there be appeal to the facts ' of which every one will be competent to judge for himself'. In 1820 Mackenzie chose for the motto of his Illustrations of phrenology the dictum that 'the most effectual method' of checking error in science was 'to multiply, as far as possible, the number of those who ean observe and judge'. Truth in mental seience was therefore to be guaranteed by a participatory form of inquiry, based on facts that an ordinary person might observe for himself. Empiricist phrenology demanded participation, legitimated participation, and, reciprocally, used wide social participation as a sign of its validity. By 1836 The Scotsman could refer to phrenology as 'a system whose popularity is a strong presumption of its truth' 56

The Edinburgh phrenologists' emphasis on empirical methods points towards differences between them and the moral philosophers as to who was capable of discovering truth and assessing claims of true knowledge. The social reference of many phrenologists was their community of adherents in the wider Edinburgh society (and perhaps this is why they were so little disturbed from their course by the damning judgments of expert elites in moral philosophy and medicine). In the dispute between Sir William Hamilton and George Combe, the latter continually endeavoured to make the debate public, to get the respective arguments on either side published, to let the public be the arbiter of truth. The idea that the dispute be resolved by the

\footnotetext{
${ }_{54}^{4}$ Gibbon (footnote 25), vol. 1, 114.

55 [George Combe], 'Explanation of the physiognomieal system of Drs Gall and Spurzheim ', Scots magazine, 79 (1817), 243-250 (p. 250).

36 'Chair of logie', The Scotsman, 29 June 1836. Ths Scotsman was then supporting Combe in his contest with Hamilton and Isaac Taylor for the Edinburgh Logic Chair. Of course, anti-phrenologists as frequently cited the popularity of phrenology among the 'vulgar' as a strong presumption of its falsehood.
} 
decision of qualified arbiters stemmed from the anti-phrenologists. Combe said:

The object of both of us ought to be to enlighten and convince the public on the subject in dispute; but how can this be accomplished by a private discussion before individual arbiters . . .? In a matter of philosophy, no one thinks of believing on mere authority, if fact and argument are within reach of his own mind. ${ }^{57}$

While Hamilton insisted on judgement by a trained and competent elite, Combe, with his insistence upon universally observable facts, claimed that 'there are ... at least an hundred thousand educated men in Britain every way qualified to judge of the points in dispute, ${ }^{58}$ Phrenologists, as Cantor notices, could even assert that "any man of ordinary understanding may, in a single day, qualify himself as thoroughly for entering upon the study of phrenology, as the profoundest physician who ever lived'. ${ }^{59}$ They were committed to this position as, I believe, they were committed to empiricism because they had a prior and more fundamental commitment to anti-elitism in knowledge and broad participation in culture. This is not to say that there were 'facts' or 'observables' upon which ' every one' could agree; as Cantor shows, there obviously were no such entities. The point is not that the phrenologists' empiricism was a valid and valuable scientific methodology, even in its own terms; rather, the point is that empiricist methodological rationalisations legitimated broader social participation in scientific culture and served to undermine the methodological prescriptions of the moral philosophers in the eyes of the phrenologists' audience.

The phrenologists attempted to discredit the moral philosophers by criticising the method of introspection. In so doing, they portrayed introspection as the method of an arrogant elite, determined to limit public participation in culture by throwing a fog of confusion over the nature of scientific inquiry. The phrenologists saw the method of introspection as mystification, and the rhetoric they used to excoriate it is indicative of how they felt an elite used method to mask reality from public scrutiny. George Combe, having abandoned his classical studies at the University of Edinburgh and having come to the conclusion that they served ' to sow the seeds of Toryism in the yet undeveloped average mind ', felt that the academic philosophy of mind had been presented ' as a mystery too profound to be penetrated by human intelligence' ${ }^{60}$ When he began to be persuaded of the value of phrenology in 1817 , he contrasted its accessibility to the philosophy of Dugald Stewart which he had been taught, and which "only proclaimed the thickness

57 ' Controversy with Sir William Hamilton' (footnote 36), 398.

58 lbid., 402. Even those not especially favourably disposed towards phrenology could draw upon an image of science to criticise moral philosophy; for example, 'The true characteristic of science consists in this - that it is a thing which can be communicated to, and made use of by, all men who are endowed with an adequate share of mere intellect. The philosophy of moral feeling must always, on the other hand, approach nearer to the nature of poetry...' (Lockhart (footnote 19), vol. 1, 183).

59 "Review of Roget's article "Cranioscopy" in the Encyclopedia britannica', Phrenological journal, 1 (1823-24), 176. Later on, especially after the founding of the national Phrenological Association, the phrenological elite became very concerned about the activities of impexfectly trained 'quacks' and impostors.

${ }_{60}$ Gibbon (footnote 25), vol. 1, 59, 93. 
of the veil which seemed to hang over [the moral philosophers'] course '.61 'Metaphysics . . . surpassed his powers of comprehension' ${ }^{62}$

Now there is nothing in the moral philosophers' stated methodology which would logically lead one to the view that it was elitist, arbitrary, authoritarian or set against empirical testing of its conclusions. In fact, Hamilton could characterise the introspective method as an essentially 'democratic' path towards truth by emphasising the dialectical nature of the process. The hearer of a moral philosophy lecture was recommended to check the results of the professor's introspection against his own self-reflection. In this way, 'critical reflection' and 'critical debate' (attributes of anti-authoritarian science) were argued to be fundamental to the methodology of academic mental philosophy. ${ }^{63}$ But the Edinburgh phrenologists seemed bent on portraying the mental philosophers' methods as suspect, subjective and elitist:

Metaphysicians adopted the method of studying their own consciousness, and that method has been found wanting; for the instant that a man compares himself with another man, he discovers so great a variation in his consciousness from that of his own, that he can no longer set himself up as a standard ...

It is therefore evident, that it is by observation alone that man can be known. ${ }^{64}$

Thus, two social dimensions entered into the debate over appropriate methodology in mental philosophy. The first was the question of whether or not one had a prior commitment to the existence of fundamental individual differences among members of a society. The second was the question of whether or not one believed that a real introspective dialectic among representative members of a society could, or did, take place - in the university or elsewhere.

I have already mentioned the phrenologists' prior commitment to innate individual differences, and I have advanced reasons why such a group in Edinburgh society might find theories stressing social variation satisfying and appropriate. On the other side, the mental philosophers' overarching concern with 'common sense', with those attributes which all members of a society had in common, not only justified their introspective methods but also reflected a social commitment. As the sympathetic George Davie puts it:

For the philosophers of the common-sense school the basis of knowledge and objective science isn't simply experimentation or observation in regard to bodies and behaviour, but the instinctive and fundamental fact of the conscious intellectual rapport between the members of a given society, which consists in their faculty of putting themselves at one another's point of view ... ${ }^{65}$

The introduction of divisions in society, especially the onset of overspecialisation caused by industrialisation, was therefore seen by Smith and Reid as endangering 'the standards of science itself'. If one sector of society could

${ }^{61}$ Combe (footnote 55), 244.

${ }^{82}$ Gibbon (footnote 25), vo1. 1, 92.

${ }_{63}$ Davie (footnote 49), 16-17.

${ }^{64} \operatorname{Sir}$ G. S. Mackenzie, Bart., General observations on the principles of education: for the use of Mechanics' Institutions (Edinburgh, 1836), 12. Compare a similar statement by a phrenologist in 'Comparative merits of the mental philosophy of the school of Reid and Stewart and of the phrenologists', Phrenological journal, 10 (1836-37), 301-337 (p. 304): 'Reid's philosophy never ean give an explanation of the differences between the mental capacity of one man and that of another, because it is confined in its basis to the mind of the individual who studies it ',

${ }^{65}$ Davie (footnote 49), 11; my italies. 
no longer effectively communicate with another, then the essential social dialectical aspect of introspection would be stopped. But the great social purpose of the Scottish school of common-sense philosophy, particularly as it was deployed in education, was to ward off the atomisation of society, to form a bulwark against individualism, and to ensure that the fabric of Scottish society was not rent with social cleavages. The aim was to encourage a 'mentality which will counteract the atomisation by building a sort of intellectual bridge between all classes, including especially the new and increasingly important class of industrial operatives, .66

However, while the Edinburgh cultural elite might elaborate a philosophy which was dependent upon social solidarity and which aimed at preserving it, other sectors of that society believed that solidarity and communality of interests no longer existed. In this way, the 'democratic intellect' of the Scottish universities could be seen, from the outside, as patronising, elitist and fundamentally flawed. It should not be surprising therefore that the cry for the reform of the universities in the 1820 s and. 1830 s came not from 'Anglicizing Scots ', as Davie would have it, but from the same emergent mercantile classes which supported phrenology. ${ }^{67}$ The mercantile classes and 'industrial operatives' who were to be the objects of the academic philosophers' benevolence did not feel that they had access to the university or to the community of discourse presided over by the Edinburgh cultural elite. When they formed their own educational institutions in the $1830 \mathrm{~s}$, they offered phrenology - not common-sense philosophy.

I have attempted to show that the Edinburgh phrenologists' commitment to what their academic opponents scorned as 'idiotey grafted upon empiricism '68 derived from their social values and interests. Against their emphasis upon observation as a sound basis for science, the phrenologists set the ' hidden' and 'mysterious' nature of academic mental philosophy. It was absolutely central to the phrenologists' social commitment that a minimallytrained individual be able to 'read off' mental character from observation of the human skull. ${ }^{69}$ Mental traits could, they argued, be inferred from surface observables. Their methodology was profoundly based on superficiality. As the phrenologists' empiricism both reflected their conflict with the academic elite and legitimated public participation in mental science, they could brook no obstacle to the validity of superficial observation. Thus, I would argue, the issue of the frontal sinuses was central to the debate between Combe and Hamilton on social grounds.

The question at issue, as Cantor well describes it, was whether frontal sinuses existed; whether, if they did, they were to be found in all adults; and

66 Ibid., 8.

${ }^{67}$ George E. Davie, The democratic intellect: Scotland and her universities in the nineteenth century (2nd ed, Edinburgh, 1964). My criticism of Davie's view of Scottish university reform derives partly from my own fortheoming work on the Edinburgh Sehool of Arts and Philosophical Association and partly from a paper given by Donald Withrington of Aberdeen University to the Scottish Society for the History of Education in 1974. One very frequently finds support for Scottish university reform in the $1820 \mathrm{~s}$ and $1830 \mathrm{~s}$ conjoined with antipathy towards academie philosophy and the advocacy of phrenology, for example, in The Scotsman and in the reports of the middle-class Philosophical Association.

${ }^{6}$ Sir William Hamilton and phrenology (footnote 33), 29.

69 One Phrenological Society member felt that such a capacity was in bad taste and preferred that it be restricted to children's heads (Scott (footnote 46), 55). 
whether they were of a size which caused significant lack of parallelism between the shape of the skull and the contours of the brain underneath. Hamilton, the metaphysician, was well advised to adopt the role of the cerebral anatomist in this controversy, for, if the frontal sinuses existed and if they could be shown to be of significant dimensions, the phrenologists' superficial empiricism could, he thought, be undermined. Hamilton, in his own words ' a mere interloper in anatomy', focused on the question of the sinuses in an attempt to show that no one (and especially not the untrained) could 'read off' mental faculties from the shape of the skull. He wanted to attack 'the persuasion, that the skull interposed no impediment to an estimation of cerebral proportions ', 70 Hamilton, who would not have credited phrenology even if he were shown that the frontal sinuses did not exist, attacked on the phrenologists' chosen groundthe observable 'facts'. Although the evidence seemed strongly in Hamilton's favour, the phrenologists, who constantly appealed to superficially observable 'facts', were not converted. Nor, it seems, could they be. It was essential to the Edinburgh phrenologists' social programme and prior social commitment that truth could be easily 'read off' from surface appearances. This is why the issue of the frontal sinuses aroused such deep emotions in the controversy, and this is why evidence could not convert either side.

The phrenologists and the academic mental philosophers, to be sure, held incommensurable points of view. And, as Cantor says, they also adhered to ineommensurable methodological programmes. But an explanation of their controversy does not stop with the identification of methodological and conceptual incommensurables. It does not stop there because we can find the source of their intellectual conflict and trace its roots to social conflict, differing social experiences, values and interests. The phrenologists' naive empiricism legitimated the capacity of the ordinary man to discover truth-truth which might then be used to advance his interests. The academic mental philosophers' method of self-reflection could then be portrayed as unscientific obfuscationnot because there was anything about introspection which of necessity restricted its use to an arrogant and biased elite but because the academic method was in fact locally associated with a resented elite.

\section{The social meaning of ceteris paribus}

Thus far I have tried to offer a social explanation of the various positions taken up by the Edinburgh phrenologists and their adversaries. I should now like briefly to deal with what appears to be a change in the phrenologists' beliefs over time and advance a social interpretation of that apparent change. Cantor points out that early phrenological writings seem to have placed a heavy emphasis on 'nature' as opposed to 'nurture', that is, they seemed to have explained behaviour on the basis of innately laid down cerebral factors and minimised the role played by the environment acting on those factors. Later on, Cantor suggests (perhaps after that 'watershed' year 1828?), Edinburgh phrenology became more environmentalist. Cantor also suggests that one of the few changes in phrenological theory which can in some way be attributed to the controversy is the elaboration of the ceteris paribus qualification to the third basic principle. Perhaps the detailed form of the ceteris paribus

70 'Controversy with Sir William Hamilton' (footnote 36), 399-400. 
modification indicates that the mental philosophers' arguments really were 'getting through'; perhaps there is a fundamental form of rationality which can on occasion overcome incommensurability; perhaps it shows that the phrenologists were obliged, in the face of the evidence arrayed against them, to accommodate their opponents' arguments and to retreat from their strong formulation? ${ }^{71}$

I think the ceteris paribus modification indicates nothing of the kind, and I shall maintain that a social explanation makes sense of the controversy by treating these apparent changes in doctrine and deployment as epiphenomena of the underlying social cleavages. I have already tried to show that Edinburgh phrenology was associated with social reformism from the outset. It also possessed elements of environmentalism from the beginning of its local career. However, Cantor is right to the extent that the sheer mass of environmentalist phrenological writing in Edinburgh increases over time. This I take as a measure of a 'time-lag' in adapting a set of Continental ideas, with their Continental associations, to British social purposes. Thus in 1825 a Phrenological Society member gave clear expression to differences between phrenology at the present time and what it should become:

Our science, inregard to the extent of its application is comparatively in its infancy, - we have not had time to bring it to bear on this important subject, - . . . and it is not in a day or a year that we can . . see more clearly ... the bearing of phrenological principles on the intricate and perplexing subject of politics. ${ }^{72}$

Spurzheim began the work of adapting phrenology to its British environment and Combe continued and completed it. But the first Edinburgh phrenological writings were very little more than glosses upon Gall and Spurzheim, intended to expound and gain popularity for the founders' work. Now there is no logical reason why Gall's system, as it stood, should not have served the purpose of legitimating social reform. Pure hereditarian ideas may serve as well as pure environmentalist ideas in legitimating tolerance, liberality and social justice. But, as it happened, Gall's Continental formulations had been deployed in a manner unpalatable to Edinburgh reformists.

Why, then, should the early elaborators of phrenology in Edinburgh, as I have portrayed them, be attracted to Gall's phrenological doctrines? The answer lies primarily in the outsider social and cultural status of people like the Combes and many of the members of the Phrenological Society. By adhering to a system which emphasised nature over nurture the early Edinburgh phrenologists were, in effect, waving a red flag in the faces of the academic mental philosophers and their Enlightenment commitments. They were symbolically expressing their antipathy to the institutionalised thought of the local elite. The initial function of phrenological ideas in the Edinburgh context was accomplished simply by deploying them in public opposition to the accepted canons of the academic elite. The phrenologists were saying ' not $\mathrm{A}$ ' to the insiders' ' $\mathrm{A}$ '. ${ }^{73}$ All sorts of individuals, for all kinds of

71 The ceteris paribus provision appears in Gall's work, but it is not stressed. It was the work of the Edinburgh phrenologists to give it a full expression and to link it to a positive social programme.

${ }^{72}$ George Lyon, ${ }^{2}$ Essay on the eauses of the different degrees of liberty enjoyed by different nations ', Phrenological journal, 2 (1824-25), 598-619 (p. 599); my italics. See also footnotes 43 and 45 above.

${ }^{73}$ Compare Douglas's treatment of early Christian Arianism in (footnote 7), 163. 
idiosyncratic personal reasons, might wish to associate themselves with such an exercise; they might wish to 'take the mental philosophers down a peg'. An aristocrat, an advocate, or even a professor might therefore be idiosyncratically disposed to adopt phrenology. In fact, one does find such insiders (like the eccentric Sir George Stewart Mackenzie) espousing phrenology . Yet the group as a whole is quite definitely an outsider group and the deployment of its ideas has to be understood in terms of the values and interests of Edinburgh outsiders.

Since social reformism was an integral part of the Edinburgh phrenologists' programme, the elaboration of environmentalist formulations may be seen as a tactic they used to legitimate reform - not because they logically needed environmentalist formulations to embark upon social reform, but because in that cultural setting environmentalism was a cultural resource associated with reformist arguments. Thus, as Cantor and Davie both point out, some individuals accepting the common-sense philosophy advocated the same sorts of social reforms as some phrenologists did and justified their doing so in terms of the environmentalism of common-sense philosophy. But this does not change the fact that academic mental philosophy was identified as the knowledge of an elite; its image was coloured by the perceived values and interests of that elite. ${ }^{74}$

So in the cultural context of early nineteenth-century Edinburgh, with its particular constellation of cultural resources and their social associations, environmentalist formulations of phrenology were a tactic which seemed to remove perceivable inconsistencies between a set of ideas and a social commitment. Within the system of phrenological ideas, the deployment and elaboration of the ceteris paribus provision served to legitimate reformist social interventions, such as educational programmes. Combe employed the ceteris paribus provision for these purposes very early in his career:

Suppose that two individuals possess an organisation exactly similar, but that one is highly educated and the other left entirely to the impulses of nature; the former will manifest his faculties with higher power than the latter; and hence it is argued, that size is not in all cases a measure of energy, . . . Education may cause the faculties to manifest themselves with the highest degree of energy which the size of the organ will permit $\ldots{ }^{75}$

Later on Combe used identieal formulations to support his liberal educational aims. ${ }^{76}$ A just social system would follow upon sound educational policy, informed by phrenological principles. And an unjust system was kept in existence by an absence of such a policy and a condition in which labouring people could not develop their higher faculties: 'Down to the present day the mass of the people, unfavourably situated for the development of their rational

\footnotetext{
${ }^{74}$ The argument I am making is, in a general form, that any set of ideas may come to serve any sort of social function. The links between ideas and social purposes is a contingent matter. While there may well be symbols or coneepts which naturally express the social experience of a given society or part of a society, such a natural association may be deflected in a differentiated society by processes like social conflict. Thus, while it is possible to argue that an outsider group like Edinburgh's mercantile class might feel a natural pull towards environmentalism, it is obliged to elaborate a set of ideas which can be publicly opposed to the thought of its social enemies.

75 George Combe, Elements of phrenology (Edinburgh, 1824), 178-179; italies in text.

${ }^{26}$ George Combe, Education: its principles and practice (ed. William Jolly: London, 1879), passim, especially pp. 263-343.
} 
nature, have remained essentially ignorant, and liable to become the tools of interested leaders, or the victims of their own blind impulses'.77 "Other things being equal ', the size of the cerebral organ could be taken as a measure of its power of function. But the factors which could be brought to bear to act against, or in assistance of, these innate propensities indicated by the size of the bump were in fact the social and political programmes to which the phrenologists and their audience were committed. The ceteris paribus formulation was not logically required; nor was it the result of the controversy. It was a good tactic which made sense in terms of the cultural context of contemporary Edinburgh and the social commitment of the phrenologistreformers.

\section{Conclusion}

My purpose in this paper has been two-fold: primarily, I was eoncerned to advance my own interpretation of the Edinburgh phrenology controversy and, secondarily, to criticise aspects of Cantor's orientation to this material. Feeling that it would be more enlightening to the reader, I presented both aspects of my purpose in their sharpest form. In doing so it has necessarily meant that less than perfect justice has been dealt to Cantor and that I have confined my alternative view to fewer aspects of the material than I should otherwise have done. It should be clear that I have in no way attempted a point-by-point 'refutation' of Cantor's interpretation; and it should be equally clear that there is much to admire in his approach. I have naturally dwelt upon issues where a social interpretation is most persuasive and may be most succinctly developed. But I see no theoretical reasons why a social approach such as the one I advance should not be successfully brought to bear upon many of the compelling issues raised by the Edinburgh phrenology controversy. If there is a single most fundamental difference between us, it is that Cantor needs to be convinced that intellectual activity is not autonomous, whereas I need to be persuaded that it is.

Finally, I should like to stress again that my approach to this material has been informed by the sociology of knowledge orientation - a body of thought which I believe may be of great assistance to the social historian of science. It does not seem to me that any of the operating principles of the sociology of knowledge are fundamentally in conflict with many taken-for-granted canons which inform historical explanation in general. Historians who attempt to integrate thought with the society in which thought occurs seem in need of no special defence. What needs to be specially justified is historical work which does not do so.

\section{Acknowledgements}

I would like to thank Madeleine Macdonald, David Bloor, Donald MacKenzie and Barry Barnes for their comments during the preparation of this article.

77 George Combe, Lectures on popular education (3rd ed., Edinburgh, 1848), 46. 